\title{
УमК 543.544
}

\section{Наноразмерные иониты - стационарные фазы для капиллярной электрохроматографии}

\author{
Д.В. Макеева, Л.А. Карцова, Д.А. Поликарпова \\ Санкт-Петербургский государственный университет, Институт химии, \\ Российская Федерация, 198504, г. Санкт-Петербург, Петродворец, Университетский пр., 26
}

*Адрес для переписки: Поликарпова Дарья Александровна, E-mail: polikdaria@yandex.ru

Поступила в редакцию 29 июня 2018 г., после исправления - 2 августа 2018 г.

\begin{abstract}
Высокая ионообменная емкость, адгезия к поверхности кварца и независимый от $\mathrm{pH}$ заряд позволяют рассматривать наноиониты в качестве перспективных модификаторов электрофоретических систем, способствующих высокоэффективному и селективному разделению аналитов. Данная работа посвящена применению наноразмерных ионитов в качестве стационарных фаз для реализации режима капиллярной электрохроматографии (КЭХ). В рамках исследования определены условия формирования покрытий стенок кварцевого капилляра на основе наноанионита и нанокатионита - сополимеров стирола и дивинилбензола, функционализированных четвертичными аммонийными и сульфогруппами, соответственно. Предложенные подходы к формированию стационарных фаз в кварцевом капилляре отличаются высокой экспрессностью (10-15 минут) и высокой воспроизводимостью от капилляра к капилляру. Полученные покрытия были охарактеризованы методом сканирующей электронной микроскопии. Высокая стабильность покрытия на основе наноанионита позволяет использовать для электрофоретического разделения фоновые электролиты с pH в диапазоне от 2 до 10 единиц; меньшая стабильность нанокатионита на поверхности кварцевого капилляра сокращает рабочий диапазон $\mathrm{pH}(2-8)$. Показаны перспективы применения кварцевых капилляров, модифицированных наноанионитом, при электрофоретическом разделении неорганических анионов и карбоновых кислот. Разделение указанных аналитов характеризуется высокой эфффективностью, большей селективностью разделения, по сравнению с результатами в отсутствие модификатора, а также экспрессностью за счет сонаправленной миграции аналитов и обращенного электроосмотического потока. Использование покрытого частицами нанокатионита капилляра позволило предотвратить сорбцию биогенных аминов при их электрофоретическом определении.

Ключевые слова: капиллярная электрохроматография, наноанионит, нанокатионит, покрытия стенок капилляра.
\end{abstract}

For citation: Analitika i kontrol' [Analytics and Control], 2018, vol. 22, no. 3, pp. 273-283 DOI: 10.15826/analitika.2018.22.3.006

\section{Nano-sized ion exchangers - stationary phases in capillary electrochromatography}

\author{
D.V. Makeeva, L.A. Kartsova, ${ }^{\star} D . A$. Polikarpova \\ Saint-Petersburg State University, Institute of Chemistry, \\ 7/9 Universitetskaya nab., St. Petersburg, 199034, Russian Federation
}

*Corresponding author: Dar'ya A. Polikarpova, E-mail: polikdaria@yandex.ru

Submitted 29 June 2018, received in revised form 2 August 2018

Nano-sized ion exchangers possess high ion exchange capacity, adhesion to quartz surface and $\mathrm{pH}$-independent charge, which make them promising stationary phases for the high-efficient and selective separation of charged analytes in the capillary electrochromatography mode. The goal of the investigation was the application of nano-sized ion exchangers as stationary phases in the capillary electrochromatography. The development of coatings based on nano-sized anion and cation exchanger (polystyrene-divinylbenzene copolymer matrix functionalized with quaternary ammonium and sulfo groups respectively) was proposed for the first time. The proposed procedures of coatings formation were very fast (less than $15 \mathrm{~min}$ ) and were 
reproducible. The characterization of coatings was also carried out by the scanning electron microscopy. The high stability of the nano-sized anion exchange coating allowed using background electrolytes with $\mathrm{pH}$ range from 2 to 10 for the electrophoretic separations. The lower stability of coatings based on nano-sized cation exchange particles of fused silica capillaries reduced the $\mathrm{pH}$ range of possible background electrolytes ( $\mathrm{pH} 2$ - 8). Modified by nano-sized anion exchangers capillaries were applied for the separation of inorganic anions and organic acids. The determination of these analytes was characterized by high efficiency, resolution (compared to the results obtained without nano-sized anion exchanger) and short analysis time due to the co-directional migration of analytes and reversed electroosmotic flow. The modification of the fused silica capillary by nano-sized cation exchange particles prevented the sorption of biogenic amines during their electrophoretic separation.

Keywords: capillary electrochromatography, nano-sized anion-exchanger, nano-sized cation-exchanger, coatings of fused silica capillary walls.

\section{ВВЕДЕНИЕ}

В последние десятилетия наночастицы (НЧ) стали активно применяться в методах разделения и концентрирования аналитов различной природы [1-6]. Высокая удельная поверхность НЧ улучшает массоперенос, что, в свою очередь, приводит к росту эффективности. Использование НЧ в качестве стационарных фаз и динамических покрытий позволяет влиять и на селективность разделения аналитов. Испытаны различные типы НЧ для электрофоретического разделения и концентрирования: фуллерены [7], углеродные нанотрубки [8], оксид графена [9], кремниевые и полимерные НЧ [10-11], оксиды металлов и металлические НЧ (например, золота и серебра) [7, 12].

Особое внимание уделяется применению наночастиц в капиллярной электрохроматографии [13]. Данный метод характеризуется значительно большей эффективностью по сравнению с ВЭЖХ и селективностью разделения в сравнении с капиллярным электрофорезом (КЭ). Традиционно, используемые в капиллярной электрохроматографии (КЭХ) колонки подразделяют на три основных типа: полые (ОТ - open-tubular), насадочные и монолитные. Полая колонка представляет собой кварцевый капилляр, внутренняя поверхность которого покрыта стационарной фазой. В отличие от насадочных и монолитных, такие колонки значительно более просты в изготовлении, характеризуются высокой проницаемостью и наибольшей эффективностью за счет отсутствия вихревой диффрузии [14]. Проблема низкого фразового отношения, характерная для полых колонок, успешно решается использованием стационарных фаз на основе наночастиц [15].

Формирование стационарной фазы на поверхности стенок капилляра возможно посредством либо ковалентной иммобилизации модификатора, либо - его физической адсорбции [13,16-21]. Первый вариант обеспечивает стабильность стационарной фазы в процессе электрофоретического анализа и высокую воспроизводимость миграционных параметров аналитов, но зачастую требует длительной процедуры модификации [13]. Физическая адсорбция модификатора, напротив, проста в исполнении, однако, стабильность сформированного покрытия может оказаться недостаточной. Та- ким образом, поиск экспрессных путей формирования в капилляре устойчивых покрытий стенок капилляра для реализации КЭХ-режима по-прежнему актуален.

Использование стационарных фраз на основе наночастиц, функционализированных ионообменными группами, позволяет разделять ионы органической и неорганической природы, сочетая при этом селективность ионной хроматографии и высокую эффективность капиллярного электрофореза [22]. В [23] наночастицы латекса с четвертичными аммонийными группами, использованы в качестве физически-адсорбированных покрытий стенок капилляра при разделении неорганических анионов в КЭХ-режиме. Модификация поверхности привела к обращению электроосмотического потока (ЭОП). Реализация КЭХ-режима на этих колонках позволяет с высокой чувствительностью определять следовые количества неорганических анионов. Сочетание полых колонок, покрытых функционализированными частицами латекса, с таким вариантом внутрикапиллярного концентрирования как стэкинг с усилением поля позволило авторам определять следовые количества нитритов и нитратов в пробах мочи и плазмы крови с пределами обнаружения до 1 нг/мл. Использование полых колонок для КЭХ со стационарной фазой на основе функционализированных наночастиц полистирола обеспечило разделение смесей белков и пептидов с эффективностью до 1900000 т.т./м [11], а бромат-ионов в водопроводной воде с пределами обнаружения 8 нг/мл [24].

Полученные в [25] наноиониты способны создавать устойчивые водные суспензии, несут независимый от $\mathrm{pH}$ заряд и обладают высокой ионообменной емкостью, что позволяет рассматривать их в качестве перспективных модификаторов электрофоретических систем. Наноанионит характеризуется высокой адгезией к поверхности кварца, что может приводить к формированию прочного покрытия на стенках капилляра.

Данная работа посвящена поиску условий формирования ионообменных покрытий стенок кварцевого капилляра на основе частиц наноразмерных ионитов (катионита и анионита) размером от 50 до 250 нм с целью реализации режима капиллярной электрохроматографии для разделения 
Characteristics of nano-sized ion exchangers [25]

\begin{tabular}{|c|c|c|}
\hline \multirow{2}{*}{ Матрица } & НИА & НИК \\
\cline { 2 - 3 } & \multicolumn{2}{|c|}{ Сополимер стирола и 8 \% дивинилбензола (рис. 1A) } \\
\hline Ионообменные группы & $\begin{array}{c}\text { Четвертичные аммонийные } \\
\text { группы }\end{array}$ & \multicolumn{2}{|c|}{ Сульфогруппы } \\
\hline Размеры частиц & \multicolumn{2}{|c|}{$50-250$ нм (рис. 1B) } \\
\hline $\begin{array}{c}\text { Концентрация по функциональным } \\
\text { группам, мМ }\end{array}$ & 43.0 & 3.4 \\
\hline Концентрация, по твердой фразе, г/л & 17.0 & 3.3 \\
\hline
\end{tabular}

различных аналитов ионогенной природы. Ранее нами была показана сама возможность модификации стенок кварцевого капилляра суспензией наноанионита на основе полистирола и дивинилбензола с терминальными четвертичными аммонийными группами, сопровождаемая генерацией обращенного электроосмотического потока [26, 27]. Обнаруженные перспективы такого подхода для решения ряда аналитических задач реализованы в данном исследовании и сопоставлены с полученными результатами для соответствующего нанокатионита с сульфогруппами.

\section{ЭКСПЕРИМЕНТАЛЬНАЯ ЧАСТЬ}

\section{Реагенты}

Концентрированная соляная кислота («Вектон»); дигидрофосфат натрия двуводный («х.ч.») («Реахим»); фоосфорная и уксусная кислоты («х.ч.») («Реахим»); борная кислота («Х.ч.») («Реахим»); гидроксид натрия («ч.д.а.») («Химреактив»); диэтаноламин (ДЭА) («Х.ч.», «Biochem»), диметилформамид (СК «Гранд»), бензойная кислота («ч.д.а.», «Sigma»), бензиловый спирт («Реахим»), ацетат аммония («Вектон»).
В качестве модификаторов стенок кварцевого капилляра, для реализации КЭХ-режима использовались:

- водная безэлектролитная суспензия наноанионита типа АВ-17x8 в ОН-фрорме (НИА);

- водная безэлектролитная суспензия нанокатионита типа КУ- 2/Н в Н-фрорме (НИК).

Данные наноразмерные модификаторы были получены в научной группе д.Х.н. А.М. Долгоносова по схеме, описанной в [25]. Характеристики модификаторов представлены в табл. 1.

\section{Оборудование}

Электрофоретические эксперименты проводились на системе капиллярного электрофореза «Капель-105М» со спектрофотометрическим детектором (НПО «Люмэкс», г.Санкт-Петербург). Источник света - дейтериевая лампа. Диспергирующий элемент - дифракционный монохроматор со спектральным диапазоном работы 190-380 нм. Охлаждение капилляра - жидкостное с заданием и контролем температуры теплоносителя (диапазон от $+10^{\circ} \mathrm{C}$ до +50 으. Способ ввода пробы: гидродинамический или электрокинетический. Смена проб автоматическая с автосемплером на 10 входных и 10 выходных пробирок. Промывка капилляра - автоматическая, под давлением 1000 мбар. Прибор
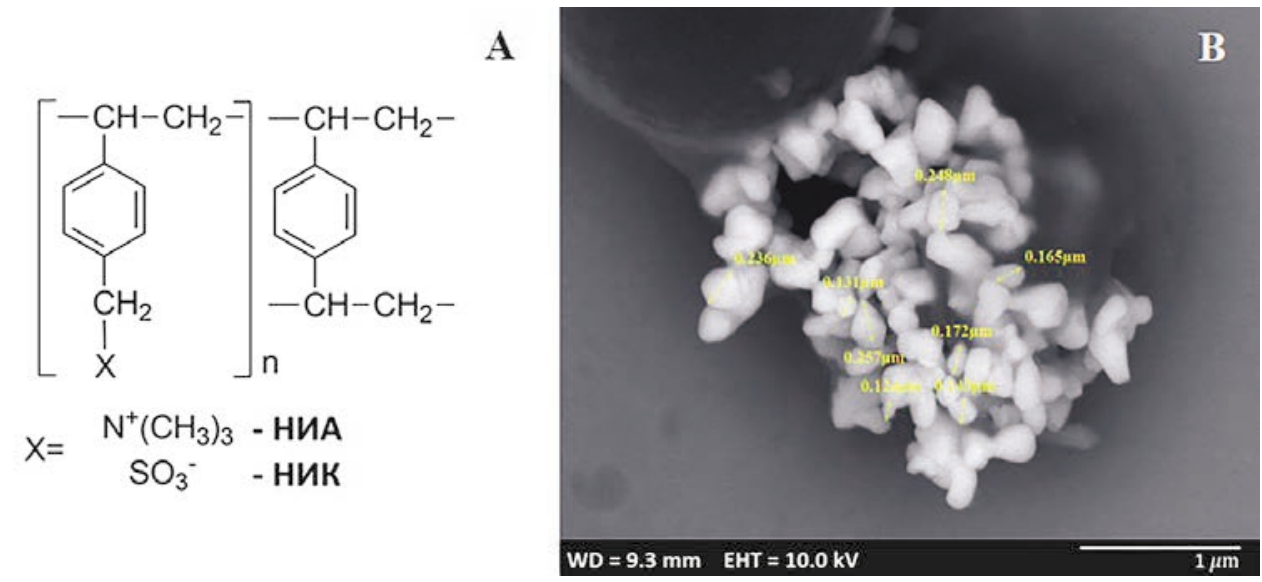

Рис. 1. (А) Функционализированная полистирол-дивинилбензольная матрица и (В) микрофотографии частиц HИA [25]

Fig. 1. (A) Functionalized polystyrene-divynilbenzene copolymer matrix and (B) electronic microphotographs of NSAE [25] 
снабжен кварцевым капилляром с внешним полиимидным покрытием (внутренний диаметр 50 мкм, общая длина 60 см, эффрективная длина $50 \mathrm{~cm}$ ).

Обработку результатов электрофоретических экспериментов проводили с помощью программного обеспечения «Эльфоран» («Люмэкс»).

Используемые средства измерений:

- микродозаторы переменного объема вместимостью 200 - 1000, 10 - 100, 20 - 200 мм³ $^{3}$ предел допускаемой погрешности измерения не более $\pm 5 \%$. - лабораторный рH-метр $\mathrm{pH}$ 211, Hanna Instruments. - аналитические весы “Sartorius" ( $d=0.001$ мг (0.5 г)).

Микрофотографии внутренних поверхностей капилляров выполнены на сканирующем электронном микроскопе Zeiss Merlin.

\section{Приготовление фоновых электролитов}

В работе использовались фоновые электролиты (ФЭ) следующего состава:

- 300 мМ боратные буфрерные растворы (pH = 7.9; 9.0; 10.0): в 45 мл деионизованной воды растворяли 0.95 г $_{3} \mathrm{BO}_{3}$, требуемого значения $\mathrm{pH}$ (по рH-метру) достигали с помощью $2 \mathrm{M}$ раствора $\mathrm{NaOH}$ и затем доводили деионизованной водой до 50 мл в мерной колбе;

- 50 мМ фоссратные буфрерные растворы ( $\mathrm{pH}=3.0$; 4.0): в 45 мл деионизованной воды растворяли 0.39 г $\mathrm{NaH}_{2} \mathrm{PO}_{4} \cdot 2 \mathrm{H}_{2} \mathrm{O}$, достигая требуемого значения $\mathrm{pH}$ $0.1 \mathrm{M}$ раствором $\mathrm{H}_{3} \mathrm{PO}_{4}$, и затем доводили объем деионизованной водой до 50 мл в мерной колбе. Аналогичным образом готовили 10 мМ фосфатный буферный раствор ( $\mathrm{pH} 2.3)$;

- 50 мМ фоосфатный фоновый электролит $(\mathrm{pH}=$ $5.4 ; 6.4):$ в 45 мл деионизованной воды растворяли 0.39 г $\mathrm{NaH}_{2} \mathrm{PO}_{4} \cdot 2 \mathrm{H}_{2} \mathrm{O}$. Соответствующего значения $\mathrm{pH}$ достигали $2 \mathrm{M}$ раствором $\mathrm{NaOH}$, после чего доводили объем деионизованной водой до 50 мл в мерной колбе;

- 100 мМ ацетатный фоновый электролит ( $\mathrm{pH}=2$; 3; 4; 5): в 90 мл деионизованной воды растворяли 0.77 г ацетата аммония, доводили до нужного значения $\mathrm{pH}$ уксусной кислотой и затем доводили объем деионизованной водой до 100 мл;

- фоновые электролиты на основе бензойной кислоты и диаэтаноламина готовили последовательным смешением в эппендорфах 500 мкл 20 мМ раствора бензойной кислоты (0.122 г растворяли в 100 мл деионизованной воды), 25, 50, 75 или 200 мкл 100 мМ раствора ДЭА (2.1 г растворяли в 100 мл деионизованной воды) с доведением общего объема полученной смеси до 1 мл деионизованной водой.

Все фоновые электролиты непосредственно перед проведением электрофоретических экспериментов отфильтровывали через бумажный фильтр и дегазировали на ультразвуковой бане. Для получения фоновых электролитов с меньшей концентрацией исходный фоновый электролит разбавлялся требуемым количеством деионизованной воды.

\section{Формирование покрытий стенок кварцевого капилляра наноанионитом}

Перед началом проведения электрофоретических экспериментов кварцевый капилляр промывали деионизованной водой (5 минут); $0.1 \mathrm{M} \mathrm{рас-}$ твором $\mathrm{HCl}$ (10 мин), затем опять водой (5 минут); $0.5 \mathrm{M}$ раствором $\mathrm{NaOH}$ (2 часа) и деионизованной водой (10 минут). Варьировали условия модификации кварцевого капилляра, промывая его водным раствором НИА в концентрациях 0.005, 0.01, 0.05, 0.1 мМ (по функциональным группам) в течение 5 , 10, 15, 30 и 45 минут; 10 минут дистиллированной водой и 10 минут 10 мМ ацетатным ФЭ рН 3 - фооновый электролит 1. Перед промывкой модификатором капилляр 10 минут промывали деионизованной водой. Создаваемое покрытие контролировали по величине и направлению электроосмотического потока (эОП), который измеряли в фоновом электролите 1. В качестве маркера использовался диметилформамид (ДМФА).

Для оценки стабильности образующегося покрытия последовательно измеряли величину ЭОП в 5, 10 и 20 мМ ацетатных фоновых электролитах ( $\mathrm{pH}=2,3$ и 5, соответственно) и фоновых электролитах следующего состава: 10 мМ бензойной кислоты и 10, 20, 30, 40 мМ дЭА (pH = 7, 8, 9, 10, соответственно), а затем - в обратной последовательности.

\section{Формирование покрытий стенок капилляра нанокатионитом}

Перед началом электрофоретических экспериментов кварцевый капилляр промывали дистиллированной водой (5 минут), 0.1 М раствором $\mathrm{HCl}$ (10 минут), затем опять водой (5 минут); 30 минут $0.5 \mathrm{M}$ раствором $\mathrm{NaOH}$ и деионизованной водой. При поиске условий модификации кварцевого капилляра испытаны следующие растворы модификаторов: - водные растворы НИК с концентрациями 0.005; 0.01; 0.05; 0.1 мМ (промывка капилляра 5, 15 и 30 минут); - раствор 0.05 и 0.1 мМ НИК в $0.1 \mathrm{M} \mathrm{HCl}$ (промывка 5, 10 и 20 минут).

После промывки раствором модификатора кварцевый капилляр промывали деионизованной водой в течение 5 минут, а затем 20 мМ фросфатным фоновым электролитом $\mathrm{pH}=6.4$ - фоновый электролит 2. Создаваемое покрытие контролировали по величине и направлению ЭОП (маркер - бензиловый спирт), который измеряли в фроновом электролите 2. Для оценки влияния модифрикатора на величину электроосмотического потока проведено сопоставление величины ЭОП на немодифицированном капилляре и капилляре, покрытом частицами НИК в диапазоне $\mathrm{pH}$ фонового электролита 2.3 - 10. Для этой цели использовали 2; 20; 27 и 30 мМ фосфатные фоновые электролиты ( $\mathrm{pH}=2.3 ; 3.3 ; 4.4$ и 5.4, соответственно), 20 мМ фосфратный фоновый электролит (рН = 6.4), а также 200, 70 и 35 мМ боратные фоновые электроли- 


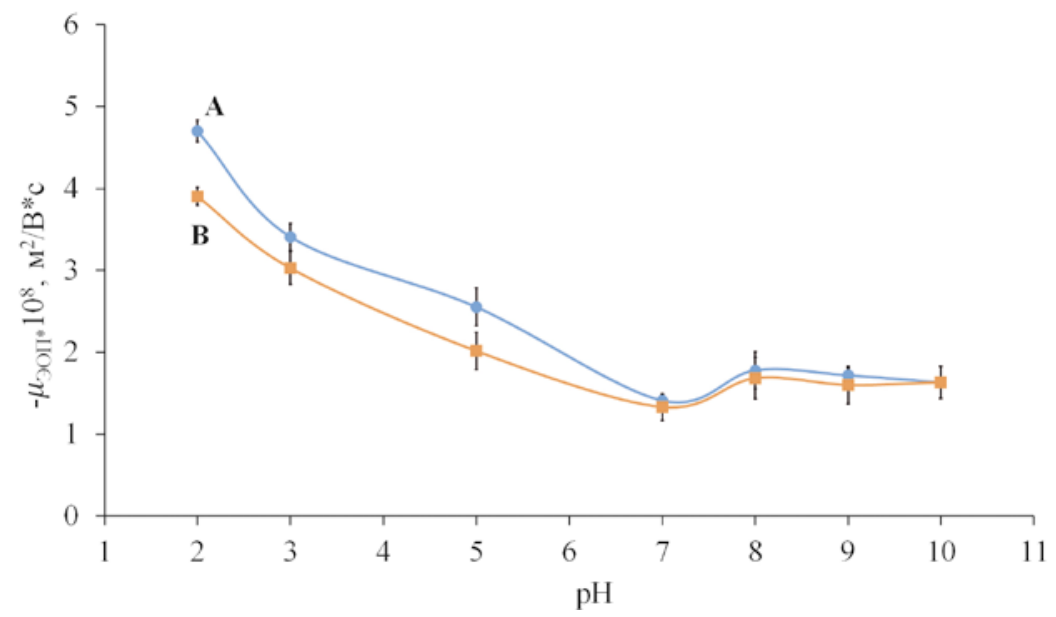

Рис. 2. Зависимость скорости ЭОП от величины рН фонового электролита на модифицированном НИА капилляре. ФЭ - ацетатный буфер $\mathrm{pH}=2 ; 3 ; 5$ (5, 10 и 20 мМ, соответственно), ФЭ на основе ДЭА и бензойной кислоты (10 мМ бензойной кислоты, 10, 20, 30 и 40 мМ ДЭА), $\mathrm{pH}=7 ; 8 ; 9 ; 10(P=0.95, n=3)$. (А) - переход от ФЭ $\mathrm{c} \mathrm{pH}=2 \mathrm{k} \mathrm{pH}=10,(\mathrm{~B})$ - обратный переход. Детектирование: прямое, 224 нм. Ввод пробы гидродинамический 5 с.30 мбар. -20 кВ

Fig. 2. Dependence of EOF mobility on pH of background electrolyte for capillary modified by nano-sized anion exchanger $(n=3)$; BGE - acetate buffer $\mathrm{pH}=2 ; 3 ; 5$ (5, 10 and $20 \mathrm{mM}$, respectively), BGE based on DEA and benzoic acid $\mathrm{pH}=7 ; 8 ; 9 ; 10$ (10 mM benzoic acid, 10, 20, 30 and 40 mM DEA, respectively). (A) - segue from pH 2 to 10, (B) from $\mathrm{pH} 10$ to 2. Detection: indirect, $224 \mathrm{~nm}$. Hydrodynamic sample injection, $5 \mathrm{~s} \cdot 30 \mathrm{mbar}$. $-20 \mathrm{kV}$

ты с рН = 7.9; 9.0 и 10.0, соответственно. Все фоновые электролиты, используемые в экспериментах с модифицированным капилляром, также содержали 0.005 мМ НИК.

\section{ОБСУЖДЕНИЕ РЕЗУЛЬТАТОВ}

Одним из важнейших аналитических приложений метода капиллярного электрофореза является определение ионных и ионогенных аналитов. Предложено и реализовано немало методик их электрофоретического определения в сложных матрицах, однако многие из них недостаточно селективны по отношению к аналитам с близкими электрофоретическими подвижностями. Возможное решение данной проблемы - реализация режима капиллярной электрохроматографии, суть которой заключается в формировании в кварцевом капилляре стационарной фазы, проявляющей способность к ионному обмену.

\section{Наноанионит - модификатор стенок кварцевого капилляра в КЭХ}

Поскольку частицы наноанионита характеризуются высокой адгезией к поверхности кварца [25], можно было бы предположить, что введение их в кварцевый капилляр приведет к модификации отрицательно заряженных стенок капилляра и обращению ЭОП. С этой целью капилляр, предварительно подготовленный к электрофоретическому анализу по схеме, описанной ранее, промывали разбавленной водной суспензией наноанионита, затем - водой для удаления избытка не сорбировавшихся на поверхности капилляра частиц и, наконец, - фроновым электролитом. Установлено, что 15-минутная промывка капилляра раствором анионита с концентрацией 0.01 мМ по функциональным группам приводит к формированию устойчивого покрытия с генерацией обращенного ЭОП.

Полученная зависимость величины ЭОП от рН фонового электролита при его изменении от 2 до 10 единиц и обратно позволяет сделать заключение, что такое варьирование условий не вызывает существенного изменения свойств покрытия (рис. 2).

Сформированное покрытие характеризуется высокой стабильностью в кислых и щелочных средах. Так, относительное среднеквадратичное отклонение (СКО) при измерении величины ЭОП в фоновом электролите 1 после 5 циклов промывки не превысило $6 \%$. Один цикл включал промывку капилляра $0.1 \mathrm{M} \mathrm{NaOH} 10$ минут, деионизованной водой - 5 минут, фооновым электролитом 1 - 10 минут. Затем проводилось измерение величины ЭОП и подобная схема повторялась еще 4 раза. Аналогичным образом подтверждена стабильность и в сильнокислой среде. Капилляр промывали 0.1 М раствором $\mathrm{HCl}$ (10 минут), деионизованной водой (5 минут), фоновым электролитом 1 (10 минут), затем измеряли скорость ЭОП; такая процедура повторялась еще 4 раза. Высокая стабильность покрытия обеспечила реализацию не менее чем 70 циклов анализа без изменения его характеристик. Достигнутая высокая стабильность покрытия обеспечила проведение электрофоретических экспериментов с использованием рН фоновых электролитов в диапазоне от 2 до 10.

Сам фракт образования такого покрытия независимо подтвержден снимками на сканирующем электронном микроскопе (рис. 3). На поверхности модифицированного капилляра обнаруживают- 


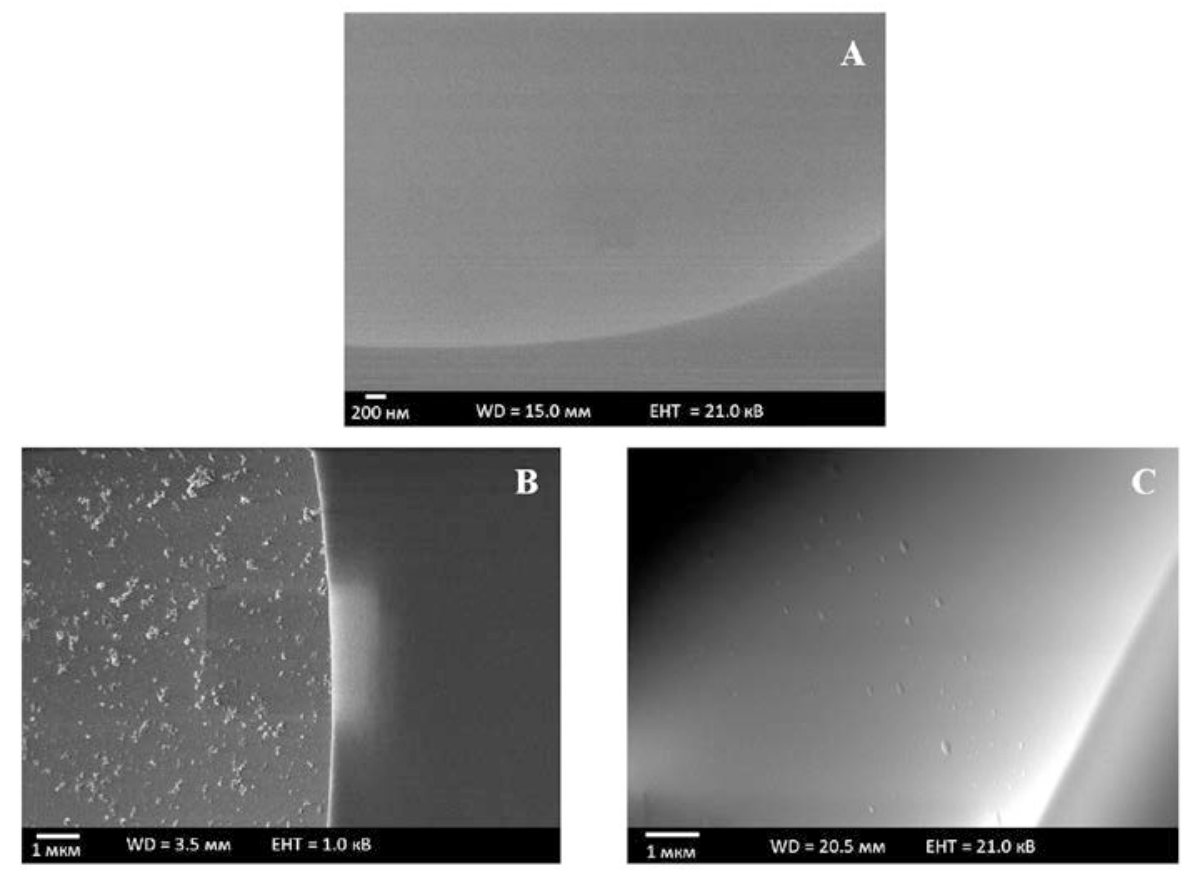

Рис. 3. Снимки немодифицированного (А), модифицированного НИА (В) и НИК (С) капилляров, полученные на сканирующем электронном микроскопе. Условия съемки: изображение во вторичных электронах

Fig. 3. Images of unmodified (A), modified by nano-sized anion exchanger (B) and nano-sized cation exchanger (C) capillaries obtained on the scanning electron microscope. The shooting conditions: image in secondary electrons

ся частицы размером 53 - 150 нм, (рис. 3В), отсутствующие на поверхности немодифицированного капилляра (рис. ЗА). Частицы НИА фрормируют на поверхности капилляра неплотный монослой, что соответствует результатам, полученным в [25]. Наличие остаточных силанольных групп на поверхности капилляра объясняет уменьшение скорости ЭОП при переходе от фонового электролита с $\mathrm{pH}$ $=3 \kappa \mathrm{pH}=10$ (рис. 2A).

Предложенный способ формирования стабильного покрытия стенок капилляра наноанионитом характеризуется высокой воспроизводимостью «от капилляра к капилляру», что было проверено при электрофоретическом разделении органических кислот на модифицированных НИА кварцевых капиллярах. Относительное значение СКО электрофоретических подвижностей аналитов, рассчитанных для 5 капилляров, не превысило 5 \%.

\section{Применение стационарной фазы на основе наноанионита}

Наличие анионообменных групп на сформированном покрытии, выполняющим роль стационарной фразы, обеспечивает разделение отрицательно заряженных аналитов. Движение обращенного ЭОП сонаправленно их миграции и заметно сокращает время анализа. Найдены условия селективного разделения неорганических анионов и карбоновых кислот с использованием модифицированных НИА капилляров (табл. 2). Показано, что в случае неорганических анионов положительный эффект на ана- литические характеристики разделения оказывает дополнительное введение частиц НИА в фоновый электролит, что обусловлено процессами ионного обмена на поверхности частиц в фоновом электролите. В отличие от неорганических анионов большая эффрективность и селективность разделения карбоновых кислот достигнуты с использованием фонового электролита, не содержащего модификатор. Подобный результат может объясняться наличием у большинства исследуемых органических кислот нескольких фрнкциональных групп, способных к взаимодействию с частицами НИА.

\section{Нанокатионит - модификатор стенок кварцевого капилляра в КЭХ}

Нанокатионит первоначально рассматривался нами как перспективная псевдостационарная фаза, введение которой в фроновый электролит будет способствовать селективному разделению положительно заряженных аналитов за счет ионного обмена на поверхности этого наноионита. Однако, установлено, что промывка капилляра в течение 15 минут 0.01 мМ водным раствором НИК приводит к уменьшению скорости ЭОП на $12 \%$, а последующая промывка 0.03 мМ раствором (15 минут) - на 26 \%; в случае использования 0.05 мМ раствора НИК (15 минут) снижение скорости ЭОП составляет уже 31 \% (величина ЭОП измерялась в фоновом электролите 2). Подобный результат свидетельствует об изменении состояния поверхности кварцевого капилляра за счет модификации наночастицами 
Таблица 2

Аналитические возможности покрытия на основе наноанионита

Table 2

Analytical capabilities of nano-sized anion exchanger coating

\begin{tabular}{|c|c|c|c|}
\hline \multirow{2}{*}{\multicolumn{2}{|c|}{$\begin{array}{c}\text { Аналитические характеристики } \\
\text { процесса разделения }\end{array}$}} & \multicolumn{2}{|r|}{ Аналиты } \\
\hline & & $\begin{array}{l}\mathrm{Br}, \mathrm{Cl}^{-}, \mathrm{NO}_{2}^{-}, \mathrm{SO}_{4}^{2-}, \mathrm{NO}_{3}^{-} \\
\mathrm{F}^{-}, \mathrm{PO}_{4}^{3-}, \mathrm{CO}_{3}^{2-}[26]\end{array}$ & $\begin{array}{c}\text { Муравьиная, щавелевая, молочная, янтар- } \\
\text { ная, яблочная, уксусная, лимонная и вин- } \\
\text { ная кислоты [27] }\end{array}$ \\
\hline \multicolumn{2}{|c|}{ Условия разделения } & $\begin{array}{c}5 \text { мМ } \mathrm{CrO}_{3}, 40 \text { мМ диэтанола- } \\
\text { мин, } 10 \% \text { МеОН с добавкой } \\
\text { НИА в концентрации } 0.05 \text { мМ }\end{array}$ & $\begin{array}{c}10 \text { мМ бензойная кислота, } 9 \text { мМ диэтанола- } \\
\text { мин }\end{array}$ \\
\hline \multicolumn{2}{|c|}{$N \cdot 10^{-3}$, т.T./M } & $128-1100$ & $130-730$ \\
\hline \multicolumn{2}{|c|}{ Rs } & $1.0-12.7$ & $1.2-5.7$ \\
\hline \multirow{2}{*}{$\begin{array}{l}\text { Пределы об- } \\
\text { наружения }\end{array}$} & $\begin{array}{c}\text { Стэкинг с усиле- } \\
\text { нием поля }\end{array}$ & $8-30$ нг/мл & $9-34$ нг/мл \\
\hline & Электростэкинг & 1 пкг/Мл - 7 нг/Мл & $1-3$ нг/Мл \\
\hline
\end{tabular}

ионита, т.е. силы адгезии превалируют над электростатическим отталкиванием одноименно заряженных частиц катионита и поверхности кварца.

Независимым свидетельством самого факта модифицирования стенок кварцевого капилляра является генерирование катодного ЭОП в фоновом электролите с $\mathrm{pH}=2.3$ (рис. 4). В этих условиях диссоциация силанольных групп подавлена, и ЭОП должен отсутствовать.

После серии предварительных экспериментов найдены условия формирования покрытия суспензией нанокатионита. Как можно видеть из рис. 4C, по мере проведения 6 последовательных 15-минутных анализов на капилляре, модификация которого проводилась промывкой суспензией НИК в деионизованной воде, наблюдается постепенное снижение величины ЭОП. Подобный результат говорит об удалении наночастиц с поверхности. Капилляр, модифицированный суспензией, разбавленной $0.1 \mathrm{M} \mathrm{HCl}$ в данных условиях демонстрирует значительно более медленную тенденцию к уменьшению значению ЭОП (рис. 4В), и, кроме того, характеризуется более высоким изна-

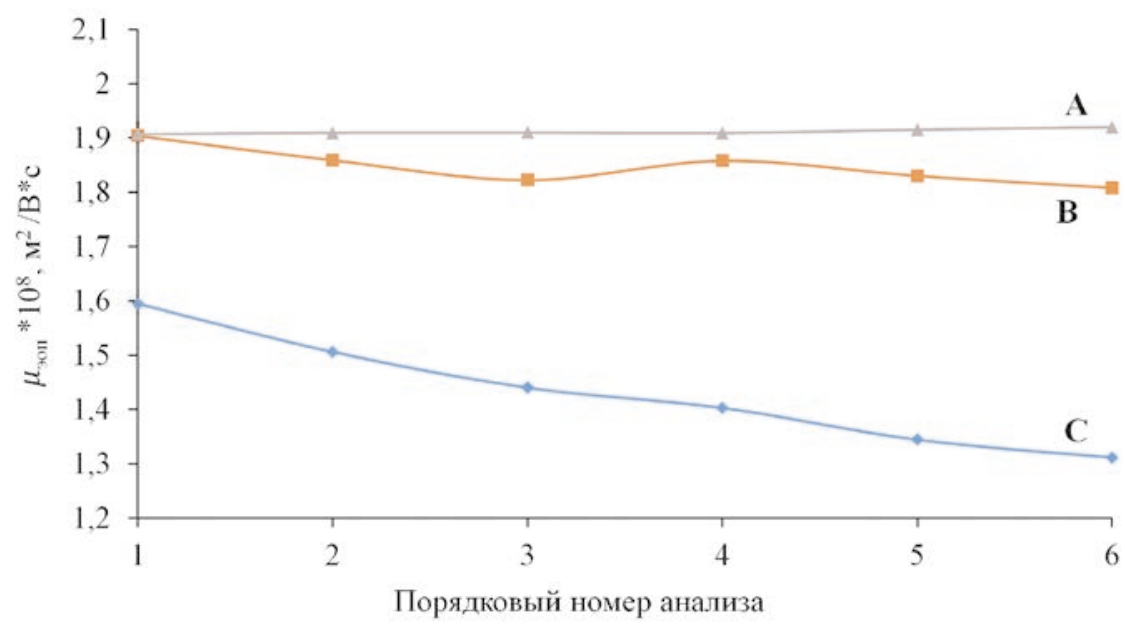

Рис. 4. Зависимость изменения скорости ЭОП от анализа к анализу для капилляров, полученных в разных условиях и фоновых электролитов с разным содержанием модификатора. (A) - формирование покрытия промывкой 0.05 мМ НИК в 0.1 М НСl (10 минут), ФЭ содержит 0.005 мМ НИК; (В) - формирование покрытия промывкой 0.05 мМ НИК в 0.1 М НСІ (10 минут), ФЭ не содержит НИК; (C) - Формирование покрытия промывкой 0.05 мМ НИК в деионизованной воде (20 минут), ФЭ не содержит НИК. Фоновый электролит: 2 мМ фосфатный фоновый электролит $\mathrm{pH}=2.3$. Детектирование: прямое, 220 нм. Ввод пробы гидродинамический 5 с.30 мбар; +20 кВ

Fig. 4. Dependence of EOF mobility from analysis to analysis on conditions of nano-sized cation exchanger coating development and nano-sized cation exchanger (NSCE) presence in the background electrolyte. (A) - 10 min rinsing of the capillary with $0.05 \mathrm{mM} N S C E$ in $0.1 \mathrm{M} \mathrm{HCl}$ for coating development, background electrolyte contains 0.005 mM NSCE; (B) - 10 min rinsing of the capillary with $0.05 \mathrm{mM}$ NSCE in $0.1 \mathrm{M} \mathrm{HCl}$ for coating development, background electrolyte without NSCE; $(C)-20$ min rinsing of the capillary with 0.05 mM NSCE in deionized water for coating development, background electrolyte without NSCE. Background electrolyte: $2 \mathrm{mM}$ phosphate buffer solution $\mathrm{pH}$ 2.3. Detection: direct, $220 \mathrm{~nm}$. Hydrodynamic sample injection $5 \mathrm{~s} \cdot 30 \mathrm{mbar} .+20 \mathrm{kV}$ 


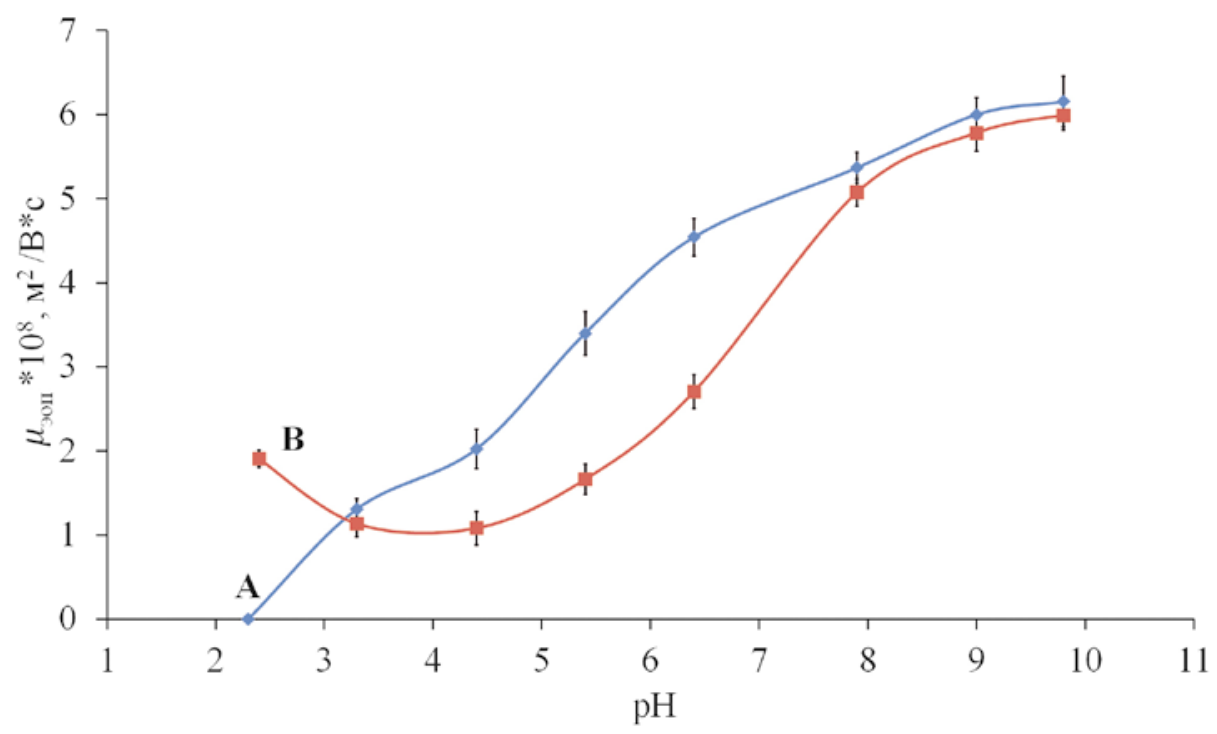

Рис. 5. Зависимость скорости ЭОП от величины рН фонового электролита. ФЭ: 2, 20, 27 и 30 мМ фосфатные ФЭ $(\mathrm{pH}=2.3,3.34 .4$ и 5.4 соответственно), 20 мМ фосфатный ФЭ $\mathrm{pH}=6.4$, а также 200, 70 и 35 мМ боратные фоновые электролиты с $\mathrm{pH}=7.9,9.0$ и 10.0 соответственно. Все ФЭ в случае модифицированного капилляра содержали 0.005 мМ НИК. (А) - немодифицированный капилляр, (В) - капилляр, модифицированный НИК. Детектирование: прямое, 220 нм. Ввод пробы гидродинамический 5 с.30 мбар; +20 кВ $(P=0.95, n=3)$

Fig. 5. Dependence of EOF mobility on pH of the background electrolyte. Background electrolyte: 2, 20, 27 and $30 \mathrm{mM}$ phosphate buffer solution ( $\mathrm{pH}=2.3,3.3,4.4$ and 5.4 respectively), $20 \mathrm{mM}$ phosphate buffer solution $\mathrm{pH}=6.4$, and 200, 70 and $35 \mathrm{mM}$ borate buffer solution $\mathrm{pH}=7.9,9.0,10.0$ respectively. All background electrolytes in the case of modified capillary contain $0.005 \mathrm{mM}$ nano-sized cation exchanger. (A) - unmodified capillary, (B) - nano-sized cation exchanger modified capillary. Detection: direct, $220 \mathrm{~nm}$. Hydrodynamic sample injection $5 \mathrm{~s} \cdot 30 \mathrm{mbar}$. +20 $\mathrm{kV}(P=0.95, n=3)$

чальным значением данной величины (точка 0 на оси абсцисс), что говорит о большей степени модификации поверхности кварцевого капилляра наночастицами. Добавка НИК в фоновый электролит в концентрации 0.005 мМ позволяет избежать удаления наночастиц и сделать величину ЭОП воспроизводимой (рис. 4А), что в свою очередь позволяет использовать капилляр для качественного и количественного электрофоретического определения катионных аналитов. Зависимость величины ЭОП от рН ФЭ на капилляре, покрытым НИК, до $\mathrm{pH}=8$ отличалась от немодифицированного капилляра (рис. 5). Значительное уменьшение скорости ЭОП при $\mathrm{pH} \leq 6.4$ объясняется частичной блокировкой части диссоциированных силанольных групп поверхности кварцевого капилляра наночастицами: уменьшение суммарного заряда поверхности приводит к снижению скорости ЭОП.

Дополнительная характеризация покрытия проведена методом СЭМ (рис. 3С). На микрофоотографрии видно наличие частиц, отсутствующих на немодифицированном капилляре. В отличие от наноанионита, они распределены по поверхности капилляра еще менее плотно, что объясняется наличием одноименного со стенками кварцевого капилляра заряда и меньшей адгезией к поверхности кварца.

\section{Стабильность стационарной фазы на основе нанокатионита на поверхности капилляра}

Установлено, что покрытие нестабильно в щелочной среде: промывка капилляра в течение 60 минут $0.1 \mathrm{M}$ раствором щелочи уменьшает величину ЭОП на $20 \%$. Работа с фоновыми электролитами со значениями $\mathrm{pH}$ выше 8 оказалась нежелательна. Установлено, что после проведения нескольких анализов в этих условиях величина ЭОП при использовании фонового электролита с $\mathrm{pH}=2.3$ уменьшается даже при наличии модификатора в его составе, что говорит о постепенной смывке покрытия. Большую стабильность сформированной стационарной фазы в кислой среде можно объяснить малой диссоциацией силанольных групп и, соответственно, более слабым электростатическим отталкиванием наночастиц от стенок капилляра.

Таким образом, рабочий диапазон капилляра ограничен применением фоновых электролитов со значениями $\mathrm{pH}$ в диапазоне 2 - 8 . В отличие от наноанионита, для поддержания стабильного ЭОП и воспроизводимых параметров миграции аналитов необходимо постоянное присутствие НИК в фоновом электролите (0.005 мМ). 


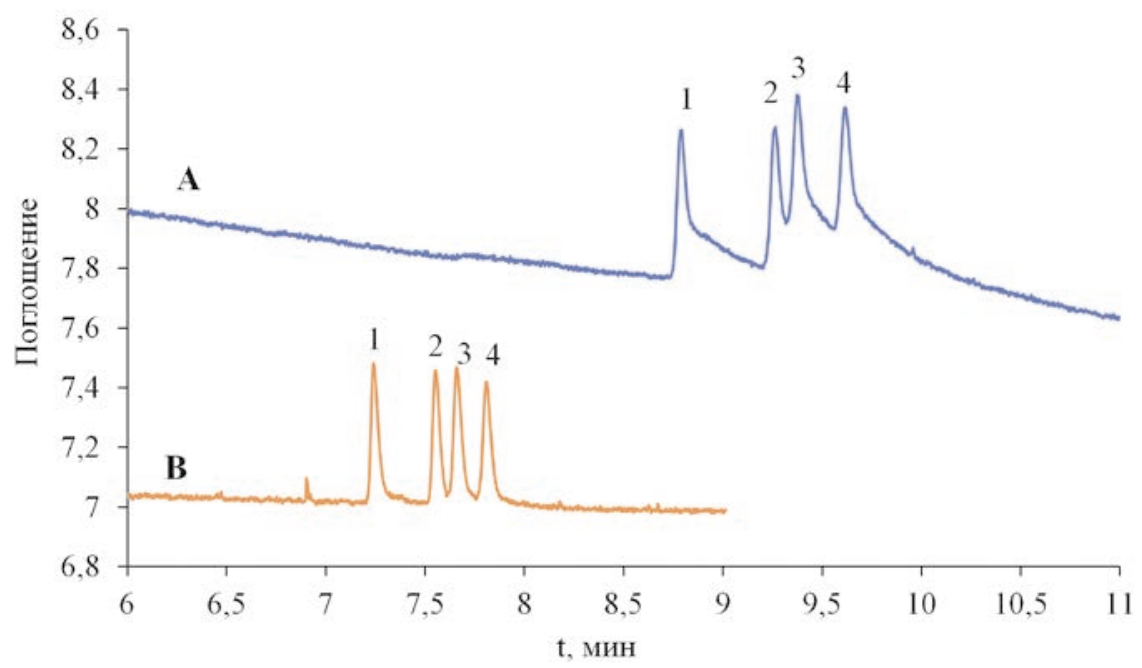

Рис. 6. Электрофореграммы модельной смеси биогенных аминов на (А) немодифицированном и (В) модифицированном НИК капиллярах. 1 - дофамин, 2 - норэпинефрин, 3 - норметанефрин, 4 - эпинефрин, концентрация 25 мкг/мл. Фоновый электролит: 10 мМ фосфатный буферный раствор $\mathrm{pH}=2$. Детектирование: прямое, 220 нм. Ввод пробы гидродинамический 2 c.30 мбар; +20 кВ

Fig. 6. Electro kinetic chromatograms of model mixture of biogenic amines on unmodified $(A)$ and nano-sized cation exchanger modified (B) capillary. 1 - dopamine, 2 - norepinephrine, 3 - normetanephrine, 4 - epinephrine, concentration $25 \mu \mathrm{g} / \mathrm{ml}$. Background electrolyte: $10 \mathrm{mM}$ phosphate buffer solution $\mathrm{pH}$ 2. Detection: direct, $220 \mathrm{~nm}$. Hydrodynamic sample injection 2 s.30mbar; +20 kV

\section{Применение стационарной фазы на основе нанокатионита}

Сформированная стационарная фраза открывает перспективы для электрофоретического анализа смесей катионных аналитов. Так, показано, что использование нанокатионита позволяет предотвратить сорбцию биогенных аминов (дофрамин, эпинефрин, норэпинефррин, норметанефрин) при их электрофоретическом определении (рис. 6). Однако пределы обнаружения этих аналитов оказались несколько выше, чем на непокрытом капилляре. Подобный эффект, очевидно, связан с собственным поглощением частиц модификатора на длине волны детектирования. Решение данной проблемы возможно при реализации внутрикапиллярного концентрирования.

\section{ЗАКЛЮЧЕНИЕ}

В рамках данного исследования рассмотрены возможности использования наноразмерных ионитов для реализации режима капиллярной электрохроматографиии. Подходы к формированию стационарных фаз на основе наноанионита и нанокатионита отличаются экспрессностью (15 и 10 минут, соответственно) и хорошей воспроизводимостью процедуры модификации от капилляра к капилляру (табл. 3). Покрытие на основе наноанионита характеризуется крайне высокой стабильностью и широким диапазоном рН используемых фоновых электролитов. Возможности покрытия реализованы при решении таких аналитических задач как определение неорганических анионов и карбоновых кислот. Покрытие на основе нанокатионита менее стабильно, однако, соблюдение ряда условий, а именно: использование фоновых электролитов со значениями $\mathrm{pH}$ в диапазоне от 2 до 8 и добавка модифрикатора в фоновый электролит при проведении

Таблица 3

Сопоставление основных характеристик стационарных фаз на основе наноионитов

Table 3

Comparison of main characteristics of stationary phases based on nano-sized ion exchangers

\begin{tabular}{|c|c|c|}
\hline Характеристика & Наноанионит & Нанокатионит \\
\hline Требуемое время модификации & 15 минут & 0.05 мМ \\
\hline $\begin{array}{c}\text { Концентрация наночастиц для проведения моди- } \\
\text { фикации (по фрункциональным группам) }\end{array}$ & 0.01 мМ & Требуется (0.005 мМ) \\
\hline Наличие модификатора в ФЭ & Не требуется & $2-8$ \\
\hline Диапазон возможных рН ФЭ & $2-10$ & 4 \\
\hline $\begin{array}{c}\text { Относительное СКО величины ЭОП на капиллярах, } \\
\text { полученных в идентичных условиях, \% }(n=5)\end{array}$ & 5 & \\
\hline
\end{tabular}


электрофоретического анализа (табл. 3) позволяет использовать эту стационарную фазу для разделения катионных аналитов в режиме капиллярной электрохроматографии.

\section{БЛАГОДАРНОСТИ}

Работа выполнена при поддержке грантов РФФИ № 17-03-01282 и 18-33-01091. Исследования проведены с использованием оборудования Междисциплинарного ресурсного центра по направлению «Нанотехнологии» и Ресурсного Образовательного Центра по направлению химия, Научный парк СПбГУ.

\section{ACKNOWLEDGMENTS}

The authors are thankful for the financial support provided by the Russian Foundation for Basic Research no. 17-03-01282 and 18-33-01091. Results were performed at the Interdisciplinary Resource Center for Nanotechnology and Chemistry Educational Center, Research Park, Saint Petersburg State University.

\section{ЛИТЕРАТУРА}

1. Nilsson C., Birnbaum S., Nilsson S. Use of nanoparticles in capillary and microchip electrochromatography // J. Chromatogr. A. 2007. V. 1168. P. 212-224.

2. Zarei M., Ghasemabadi M. Nanoparticle improved separations: From capillary to slab gel electrophoresis // TrAC. 2017. V. 86. P. 56-74.

3. Guihen E. Nanoparticles in modern separation science // TrAC. 2013. V. 46. P. 1-14.

4. Duan A., Xie S., Yuan L. Nanoparticles as stationary and pseudo-stationary phases in chromatographic and electrochromatographic separations // TrAC. 2011. V. 30. P. 484-491. 5. Hajba L., Guttman A. Recent advances in column coatings for capillary electrophoresis of proteins // TrAC. 2017. V. 90. P.3 8-44.

6. Separation of metal ions via capillary electrophoresis using a pseudostationary phase microfunctionalized with carbon nanotubes / L-Q Peng [et al.] // Microchim. Acta. 2017. V. 184. P. $1747-1754$.

7. CE coupled to MALDI with novel covalently coated capillaries / S. Bachmann [et al.] // Electrophoresis. 2010. V. 31. P. 618-629.

8. Carbon nanostructures as sorbent materials in analytical processes / M. Valcarcel [et al.] // TrAC. 2008. V. 27. P. 34-43.

9. Capillary coated with graphene oxide as stationary phase for the separation of brucine and strychnine by capillary electrophoresis / J. Li [et al.] // J. Chromatogr. Sci. 2015. V. 53. P. 641-645.

10. Permanent gold nanoparticle coatings on polyelectrolyte multilayer modified capillaries for open-tubular capillary electrochromatography / Q. Qu [et al.] // J. Chromatogr. A. 2010. V. 1217. P. 6588-6594.

11. Capillary electrophoresis of peptides and proteins fusedsilica capillaries coated with derivatized polystyrene nanoparticles / G. Kleindienst [et al.] // Electrophoresis. 1998. V. 19. P. 262-269.

12. Neiman B., Grushka E., Lev O. Use of gold nanoparticles to enhance capillary electrophoresis // Anal. Chem. 2001. V. 73. P. $5220-5227$.
13. Applications of nanoparticle-modified stationary phases in capillary electrochromatography / W. Hu [et al.] // TrAC. 2014. V. 61. P. 9-39.

14. Tang Q., Lee M. Column technology for capillary electrochromatography // TrAC. 2000. V. 19. P. 648-663.

15. Guihen E., Glennon J. Recent highlights in stationary phase design for open-tubular capillary electrochromatography // J. Chromatogr. A. 2004. V. 1044. P. 67-81.

16. Dynamic Coating Agents in CE // J. Znaleziona [et al.] // Chromatographia. 2008. V. 67. P. 5-12.

17. Simultaneous separation of acidic and basic proteins using gemini pyrrolidinium surfactants and hexafluoroisopropanol as dynamic coating additives in capillary electrophoresis / Y. Tiana [et al.] // J. Chromatogr. A. 2015. V. 1412. P. 151-158. 18. Liu C., Kang J. Improved capillary electrophoresis frontal analysis by dynamically coating the capillary with polyelectrolyte multilayers // J. Chromatogr. A. 2012. V. 1238. P. 146-151. 19. Imidazolium ionic liquids as dynamic and covalent modifiers of electrophoretic systems for determination of catecholamines / E. Kolobova [et al.] // Talanta. 2018. V. 188. P. 183-191. 20. Self-assembled and covalently linked capillary coating of diazoresin and cyclodextrin-derived dendrimer for analysis of proteins by capillary electrophoresis / B. Yu [et al.] // Talanta. 2016. V. 152. P. 76-81.

21. Dendritic glycopolymers as dynamic and covalent coating in capillary electrophoresis: View on protein separation processes and detection of nanogram-scaled albumin in biological samples / N. Polikarpov [et al.] // J. Chromatogr. A. 2015. V. 1378. P. 65-73.

22. Capillary electrochromatography using monoamineand triamine-bonded silica nanoparticles as pseudostationary phases / Y. Takeda [et al.] // J. Chromatogr. A. 2016. V. 1427. P. $170-176$.

23. Indirect spectrophotometric detection of inorganic anions in ion-exchange capillary electrochromatography / M. Boyce [et al.] // Electrophoresis. 2000. V. 21. P. 3073-3080. 24. Guo Y. Preparation and application of trimethylamine amination polychloromethyl styrene nanolatex coated capillary column for the determination of bromate by field-amplified sample stacking open-tubular capillary electrochromatography // Electrophoresis. 2013. V. 34. P. 1312-1318.

25. Получение, свойства и применение коллоидных растворов наноразмерных ионитов / А. М. Долгоносов [и др.] // Сорбционные и хроматографические процессы. 2016. T.16, №4. С.400-414.

26. Дзема Д., Карцова Л., Поликарпова Д. Применение высокоосновного наноионита в капиллярном электрофорезе для разделения и концентрирования неорганических анионов // Аналитика и контроль. 2017. Т.21, №1. C.41-48.

27. Nano-sized anion-exchangers as a stationary phase in capillary electrochromatography for separation and on-line concentration of carboxylic acids / D. Polikarpova [et al.] // Talanta. 2018. V. 188. P. 744-749.

\section{REFERENCES}

1. Nilsson C., Birnbaum S., Nilsson S. Use of nanoparticles in capillary and microchip electrochromatography. J. Chromatogr. A, 2007, vol. 1168, pp. 212-224. DOI: 10.1016/j.chroma.2007.07.018. 2. Zarei M., Ghasemabadi M. Nanoparticle improved separations: From capillary to slab gel electrophoresis. TrAC, 2017, vol. 86, pp. 56-74. DOI: 10.1016/j.trac.2016.11.004

3. Guihen E. Nanoparticles in modern separation science. TrAC, 2013, vol.46, pp.1-14. DOI: 10.1016/j.trac.2013.01.011. 
4. Duan A., Xie S., Yuan L. Nanoparticles as stationary and pseudo-stationary phases in chromatographic and electrochromatographic separations. TrAC, 2011, vol. 30, pp. 484-491. DOI: 10.1016/j.trac.2011.01.007.

5. Hajba L., Guttman A. Recent advances in column coatings for capillary electrophoresis of proteins. TrAC, 2017, vol. 90, pp. 38-44. DOI: 10.1016/j.trac.2017.02.013.

6. Peng L-Q., Ye L-H., Cao J., Du L-J., Xu J-J., Zhang Q-D. Separation of metal ions via capillary electrophoresis using a pseudostationary phase microfunctionalized with carbon nanotubes. Microchim. Acta, 2017, vol. 184, pp.1747-1754. DOI: 10.1007/s00604-017-2172-9.

7. Bachmann S., Vallant R., Bakry R., Huck C., Corradini D., Bonn G. CE coupled to MALDI with novel covalently coated capillaries. Electrophoresis, 2010, vol. 31, pp. 618-629. DOI: 10.1002/elps.200900507.

8. Valcarcel M., Cardenas S., Simonet B., Moliner-Martines Y., Lucena R. Carbon nanostructures as sorbent materials in analytical processes. TrAC, 2008, vol. 27. pp. 34-43. DOI: 10.1016/j.trac.2007.10.012.

9. Li J., Ye N., Gao C., Zhou T., Ma J. Capillary coated with graphene oxide as stationary phase for the separation of brucine and strychnine by capillary electrophoresis. J. Chromatogr. Sci., 2015, vol. 53, pp. 641-645. DOI: 10.1093/ chromsci/bmu076.

10. Qu Q., Liu D., Mangelings D., Yang C., Hu X. Permanent gold nanoparticle coatings on polyelectrolyte multilayer modified capillaries for open-tubular capillary electrochromatography. J. Chromatogr. A, 2010, vol. 1217, pp. 6588-6594. DOI: 10.1016/j. chroma.2010.08.057.

11. Kleindienst G., Huber C., Gjerde D., Yengoyan L., Bonn G. Capillary electrophoresis of peptides and proteins fused-silica capillaries coated with derivatized polystyrene nanoparticles. Electrophoresis, 1998, vol. 19, pp. 262-269. DOI: 10.1002/ elps.1150190220.

12. Neiman B., Grushka E., Lev O. Use of gold nanoparticles to enhance capillary electrophoresis. Anal. Chem., 2001, vol.73, pp. 5220-5227. DOI: 10.1021/ac0104375.

13. Hu W., Hong T., Gao X., Ji Y. Applications of nanoparticlemodified stationary phases in capillary electrochromatography. TrAC, 2014, vol. 61, pp. 9-39. DOI: 10.1016/j.trac.2014.05.011. 14. Tang Q., Lee M. Column technology for capillary electrochromatography. TrAC, 2000, vol. 19, pp. 648-663. DOI: 10.1016/S0165-9936(00)00048-0.

15. Guihen E., Glennon J. Recent highlights in stationary phase design for open-tubular capillary electrochromatography. J. Chromatogr. A, 2004, vol. 1044, pp. 67-81. DOI: 10.1016/j. chroma.2004.05.107.

16. Znaleziona J., Petr J., Knob R., Maier V., Sevcık J. Dynamic Coating Agents in CE. Chromatographia, 2008, vol. 67, pp. 5-12. DOI: 10.1365/s10337-007-0509-y.

17. Tiana Y., Li Y., Mei J., Cai B., Dong J., Shi Z., Xiao Y. Simultaneous separation of acidic and basic proteins using gemini pyrrolidinium surfactants and hexafluoroisopropanol as dynamic coating additives in capillary electrophoresis. $J$. Chromatogr. A, 2015, vol. 1412, pp. 151-158. DOI: 10.1016/j. chroma.2015.08.020.

18. Liu C., Kang J. Improved capillary electrophoresis frontal analysis by dynamically coating the capillary with polyelectrolyte multilayers. J. Chromatogr. A, 2012, vol. 1238, pp. 146-151. DOI: 10.1016/j.chroma.2012.03.043.

19. E. Kolobova, L. Kartsova, A. Kravchenko, E. Bessonova. Imidazolium ionic liquids as dynamic and covalent modifiers of electrophoretic systems for determination of catecholamines. Talanta, 2018, vol. 188, pp. 183-191. DOI: 10.1016/j. talanta.2018.05.057.

20. Yu B., Chi M., Han Y., Cong H., Tang J., Peng Q. Selfassembled and covalently linked capillary coating of diazoresin and cyclodextrin-derived dendrimer for analysis of proteins by capillary electrophoresis. Talanta, 2016, vol. 152, pp. 7681. DOI: 10.1016/j.talanta.2016.01.043.

21. N. Polikarpov, V. Potolytsyna, E. Bessonova, S. Trippa, D. Appelhans, B. Voita, L. Kartsova. Dendritic glycopolymers as dynamic and covalent coating in capillary electrophoresis: View on protein separation processes and detection of nanogramscaled albumin in biological samples. J. Chromatogr. A, 2015, vol. 1378, pp. 65-73. DOI: 10.1016/j.chroma.2014.11.051.

22. Takeda Y.,Hayashi Y., Utamura N., Takamoto C., Kinoshita M., Yamamoto S., Hayakawa T., Suzuki S. Capillary electrochromatography using monoamine- and triaminebonded silica nanoparticles as pseudostationary phases. $J$. Chromatogr. A, 2016, vol. 1427, pp. 170-176. DOI: 10.1016/j. chroma.2015.11.085.

23. Boyce M., Breadmore M., Macka M., Doble P., Haddad $P$. Indirect spectrophotometric detection of inorganic anions in ion-exchange capillary electrochromatography. Electrophoresis, 2000, vol. 21, pp. 3073-3080.

24. Guo Y. Preparation and application of trimethylamine amination polychloromethyl styrene nanolatex coated capillary column for the determination of bromate by field-amplified sample stacking open-tubular capillary electrochromatography. Electrophoresis, 2013, vol. 34, pp. 1312-1318. DOI: 10.1002/ elps.201200541.

25. Dolgonosov A., Khamizov R., Kolotilina N., Shayhina S., Yevstigneyeva P. Preparation, properties and application of the colloid solutions of nano-sized ion-exchangers. Sorption and chromatography processes, 2016, vol. 16, no.4, pp. 400 414.

26. Dzema D., Kartsova L., Polikarpova D. Application of strong basic nano-sized anionite for the capillary electrophoresis separation and on-line concentration of inorganic anions. Analitika i control', 2017, vol.21, no.1, pp. 41-48.

DOI: 10.15826/analitika.2017.21.1.004.

27. Polikarpova D., Makeeva D., Kartsova L., Dolgonosov A., Kolotilina N. Nano-sized anion-exchangers as a stationary phase in capillary electrochromatography for separation and on-line concentration of carboxylic acids. Talanta, 2018, vol. 188, pp. 744-749. DOI: 10.1016/j.talanta.2018.05.094. 